\title{
Editorial
}

\section{A resistência equilibrista. Universidade, clínica e política}

\section{The equilibrist resistance.} University, clinic, and politics

Plínio Prado*

O presente número da Revista Latinoamericana de Psico-patologia Fundamental aparece num contexto histórico-politico e cultural particular, onde a questão da Universidade ocupa de certo modo um lugar central - e com ela, a questão da clínica. Essa centralidade pode ser enunciada em três pontos.

1. Hoje é o 50 aniversário dos eventos que em 1968 colocaram em causa a Universidade e a sociedade industrial ou pós-industrial na qual ela se inseria e se insere. No Brasil, na América Latina, em «Maio» na França, na Alemanha, nos Estados Unidos, no Japão... jovens, estudantes, professores, cientistas, interrogavam a finalidade do saber, do desenvolvimento e da sociedade.

Ora, é precisamente na esteira desse movimento que emergiu na França o projeto da «clínica na Universidade»e, através dele, a problemática da «psicopatologia fundamental».

(Como se sabe, o projeto de Manoel Berlinck «se inscreve na linha direta do programa Psychanalyse à l'Université que Jean Laplanche e Jacques Lacan impulsionaram na França, cada um à sua maneira, sob o élan do movimento de 1968. [...] A história do conceito de

* Université de Paris 8 (Paris, França). 
psicopatologia fundamental, cunhado por Fédida, é indissociável dessa experiência universitária.» ${ }^{1}$ )

2. Meio século após 1968, a situação da Universidade hoje, no contexto mundial do «liberalismo cognitivista», é crítica; ela reenvia a uma crise profunda, onde se decidirá o seu destino. Lacan indicava o ponto crucial, na sequência de 1968: "a redução do saber ao serviço do mercado» (ele desenvolverá esse ponto em seguida, a partir da teoria dos quatro discursos).

O saber tornou-se com efeito, mais do que nunca, um campo de batalha no qual a política do liberalismo se aplica a anexá-lo, subordinando-o aos critérios de desempenho e de rendimento do sistema, em detrimento da missão primordial que se acha no princípio da Universidade: a de elaborar e difundir para todos um saber livre, crítico e emancipador, formador de um éthos, de um modo de ser - missão onde a pesquisa e o ensino da psicanálise têm o seu papel importante a cumprir.

Daí as mobilizações de estudantes universitários e do ensino médio que estão ocorrendo neste momento na França, contra reformas que visam, em última instância, desmantelar o projeto de uma Universidade crítica para todos.

Daí também, num outro contexto histórico-político e segundo uma outra violência, num clima particularmente obscurantista, a perseguição de que as Universidades tem sido alvo atualmente no Brasil. ${ }^{2}$

3. Sobre esse pano de fundo geral, o congresso de setembro da Associação Universitária de Pesquisa em Psicopatologia Fundamental - o primeiro que terá sido concebido sem Manoel Berlinck - terá como tema «A clínica na Universidade e além». É evidente que a nossa responsabilidade de universitários e de atores da cultura, inclusive da clínica, exige que não esqueçamos o pano de fundo rapidamente evocado aqui. Nós sabemos que Manoel Berlinck se importava profundamente com a articulação clínica/universidade (cf. Revista

${ }^{1}$ Cf. o editorial da Revista Latinoamericana de Psicopatologia Fundamental, n. 3, datado de setembro de 2016, «Ao Manoel Berlinck que eu conheci», p. 380-383.

${ }^{2}$ Manoel Berlinck sempre foi apegado à ideia de uma Universidade crítica para todos, segundo o seu desejo persistente de «reconciliar o erudito e o popular, a cultura intelectual e a cultura do povo, a qualidade elaborada e o instintivo, a poesia e a canção, a universidade e a rua.» (Revista Latinoamericana de Psicopatologia Fundamental, loc. cit., p. 376). Ele era fiel assim ao famoso projeto de encontro das massas com as ideias, das forças práticas com a razão teórica, que os séculos XIX e XX sonharam, na trilha do marxismo, com vistas à transformação do mundo, à verdadeira emancipação de mulheres e homens. 


\section{EDITORIAL}

Latinoamericana de Psicopatologia Fundamental, loc. cit., p. 380-383). O próprio advérbio «além», que figura no tema do congresso, já reclamaria uma palavra, uma reflexão sobre a questão das fronteiras da Universidade e de sua relação com o seu exterior.

As observações que seguem esboçam algumas variações em torno dessa problemática. Como se verá, elas são trabalhadas em filigrana por uma abordagem de ordem clínica. ${ }^{3}$

\section{1}

O «grande mercado mundial do conhecimento» consolida hoje o crepúsculo das Luzes modernas. O capital-conhecimento é a principal força de produção do liberalismo, indispensável ao seu desenvolvimento; e o objetivo deste é a melhoria do desempenho do sistema, o aumento de sua competitividade e o crescimento das mais-valias. O indivíduo contemporâneo não espera mais que um «progresso das ciências» que traga uma contribuição para a emancipação da humanidade, seja ela qual for.

$\mathrm{O}$ «mundo dos negócios» sufoca todo elã humano que não seja regido pelo desejo do ganho, observava Ernest Bloch (1976). Este mundo tende a sufocar assim a questão que os professores, estudantes e pesquisadores levantavam, por toda parte, durante os anos 1960: qual é a finalidade do conhecimento? Na verdade, a lógica do mercado exclui toda questão que concerne aos fins. "There is no alternative».

Um tempo de promessas terminou, um horizonte de esperança desaparece. Perda do destino dos humanos, desorientação geral: este quadro tornou-se um lugar comum.

Sobre o pano de fundo deste declínio, o Ocidente triunfante, liberal e tecnocientífico, prossegue na sua estratégia de anexar a Universidade ao mercado mundial do conhecimento, ao «mundo dos negócios», tal como nos demonstra hoje, dentre

Notemos ainda que é exatamente nesse projeto de uma Universidade crítica para todos que apostava Marielle Franco, que se reclamava dele sob o título do «bonde de Intelectuais da favela» (cf. sua tese de mestrado na Universidade Federal Fluminense, $U P P$ - A redução da favela a três letras : uma análise da política de segurança pública do Estado do Rio de Janeiro, datada de 2015.)

${ }^{3}$ Uma primeira versão foi publicado inicialmente no semanal Lundimatin \# 130 de 22 de janeiro de 2018 (en ligne: https://lundi.am/Plinio-W-PRADO). 
tantos outros dados, a degradação programada da Universidade pública no mundo, e o fim anunciado da Universidade livre para todos.

\section{2}

A onda de operações policiais do Estado, que de um ano para cá atacam a Universidade pública e os universitários no Brasil, se inscreve, à sua maneira, brutal, nesta lógica geral de anexação. Mas ela exibe ainda mais descaradamente do que em outros lugares a violência liberal (ela culminou no suicídio do reitor da Universidade Federal de Santa Catarina em outubro de 2017). Ela revela aí, mais claramente, a ferocidade da guerra de interesses (a «concorrência») já implicada e dissimulada nos termos mercado, mais-valia, seleção, privatização, ou seja, o fundo implacavelmente opressivo da «democracia capitalista».

Decerto o liberalismo mundial, consensual e de direito, nunca deixou de conviver bem com a violência, o autoritarismo, o estado de emergência, os ódios e seus crimes, «mesmo» nos «países desenvolvidos». Ele engendrou, em particular, uma nova figura do fascismo em escala mundial, encarnada pela série de chefes de Estado contemporâneos que vai de Berlusconi a Trump e para além deles, e que alguns chamam hoje de «fascismo democrático».

A violência do Estado contra a Universidade não é tampouco um apanágio do governo brasileiro (vide a Turquia de Erdogan). Mas um detalhe da atual ofensiva policial do governo de $\mathrm{M}$. Temer chama todavia a atenção. Um detalhe despropositado, carregado de significação implícita, como um lapso. Ele permite decifrar, condensado num elemento acessório e minúsculo, o sentido extremamente inquietante dos processos em marcha no país.

Trata-se dos nomes escolhidos pela Polícia Federal do Brasil para batizar as suas incursões armadas na Universidade. Essas blitze, amplamente midiáticas e violando flagrantemente os direitos mínimos garantidos pela Constituição, foram denominadas «operação PhD» (blitz do 9 de dezembro de 2016); «Operação Research» (13 de fevereiro de 2017); «Operação Esperança equilibrista» (6 de dezembro de 2017). O propósito é portanto o de acumular injúrias irônicas, proferidas gratuitamente pela Polícia Federal contra a Universidade. Expõem-se, assim, a profundidade do ódio que corrói as relações do poder governamental com a «classe intelectual», universitária e artística, assim como com tudo o que é suspeito de estar associado de perto ou de longe a algum processo de emancipação.

Que se examine de perto o último nome citado: «Operação Esperança equilibrista». A denominação da blitz designa o seu alvo: a «esperança», dita «equilibrista», ou seja, hábil em malabarismos a fim de se manter em pé apesar de todos 


\section{EDITORIAL}

os obstáculos. É no caso uma referência explícita ao tema da música símbolo da resistência contra a ditadura militar do Brasil (1964-1985), «O bêbado e a equilibrista», chamada de hino da anistia politica e dos exilados. ${ }^{4}$

O ódio a mais, que se extravasa através do detalhe da denominação, trai assim o objetivo não declarado da perseguição policial: por uma curiosa coincidência, com efeito, os universitários sumariamente presos no campus (sem qualquer procedimento formal, oficiosamente «presumidos culpados» por desvio de fundos) participavam da construção do Memorial da Anistia política, dedicado precisamente aos perseguidos pela ditadura.

Como sempre, a verdade se dissimula no detalhe. A blitz policial e a sua denominação insolente anunciam que se pretende continuar, hoje, a intimidar as correntes de emancipação que se opõem a um regime ditatorial ou autoritário, e a aprovar a perseguição delas. Com o ódio de classe, de cor e da intelligentsia que os anima, os ataques policiais à Universidade e à «esperança equilibrista» equivalem a uma verdadeira declaração de guerra ao país e ao povo, que o poder governamental impopular e ilegítimo despreza, aliás, abertamente.

No ato de ultrajar de forma provocatória um símbolo popular da resistência contra a ditadura, dá-se a ler também um futuro próximo possível, a saber: o do controle do país pelas novas forças fascistas em ascensão. É em todo o caso o que está sendo preparado nos bastidores do atual governo, representante das velhas oligarquias locais e que se distingue por sua submissão rastejante ao império dos bancos de Manhattan e aos lobbies petroleiros internacionais (M. Temer é considerado o «homem de Washington no Brasil» há muito tempo, segundo os documentos publicados no Wikileaks).

Isso explica então porque é precisamente a essa música símbolo que a Polícia Federal do atual governo volta hoje, quarenta anos depois, a fim de pisotear a sua memória. (Pensemos em N. Sarkozy na França, voltando em 2007 a quarenta anos atrás, na sua intenção proclamada de «Liquidar a herança de Maio de 68 de uma vez por todas». Quer dizer então que a coisa continua viva.)

É importante tomar toda a medida do que está em jogo. Para tanto, é necessário examinar mais de perto o que é homenageado pela música atacada. Porque é

${ }^{4}$ "O bêbado e a equilibrista», de João Bosco e Aldir Blanc, lançada em 1978 e gravada em 1979, desempenhou um papel importante na promulgação da lei da anistia política de 28 de agosto de 1979. 
essa a coisa da qual o «mundo dos negócios» nada quer saber, que ele se esforça em esquecer e em fazer esquecer, em sufocar, segundo as palavras de Bloch (1976). Mas a coisa sendo tenaz, insistente ao ponto de continuar a assombrar a «classe política» quarenta anos depois, aparece, ao contrário, como o «lugar» ou a fonte de resistência por excelência. Segue-se daí que é com ela que é, e que será necessário contar, justamente, para responder ao desafio lançado ao país pelo atual poder político e barrar a ascensão das forças fascistas que ele prepara.

A coisa é figurada alegoricamente no centro do hino da anistia: ela é «simplesmente» a força de esperar apesar de tudo. A esperança, capaz de se manter de pé e de dançar, mesmo na corda bamba, a despeito de todos os perigos. A esperança de uma existência outra, mais justa, emancipada das ditaduras, da pobreza e dos preconceitos. (Em meados dos anos 1970, quando a ditadura dos generais se aplicava em enquadrar no detalhe a vida dos Brasileiros, essa esperança tinha que ser literalmente funâmbula, acrobata. Tivemos que provar a sua dança dançando - na corda bamba. E que outra coisa poderia ser ainda a esperança hoje, no mundo como ele vai, senão equilibrista?)

As forças de polícia riem sarcasticamente hoje, com suas blitze e suas denominações injuriosas, porque na sua arrogância atual elas acreditam poder até mesmo derrubar e liquidar de uma vez por todas a esperança, jogando-a abaixo do fio no qual ela dançava. Erradicar até o desejo, até a própria ideia de um mundo outro, isso também está inscrito na lei do desenvolvimento do sistema, na qual tudo o que está programado deve ocorrer e só deve ocorrer o que está programado, segundo o modelo do «retorno sobre investimento».

No entanto, isso é ignorar que o próprio da esperança é de sempre renascer de suas cinzas. É enganar-se profundamente, portanto, sobre a força de resistência que a sustenta: a sua paixão acrobática do possível, que é a de tornar o impossível possível. Força obstinada, inesgotável dos pequenos deste mundo, que é a marca própria da existência humana. Quando procuramos um humano que seja verdadeiramente um humano, encontramos sempre um acrobata, escreve P. Sloterdijk (2011).

O hino da anistia e dos exilados conhece bem o assunto, ele que no seu elã afirma intensamente, contra tudo, a força acrobática. Ele mostra que a força de esperar persiste, irredutível, no próprio seio do sofrimento de homens e mulheres do povo, roubados, enganados, explorados, humilhados, oprimidos; ela é capaz de se manter de pé — mesmo sobre a base a mais tênue que se possa imaginar, a de um fio oscilante esticado sobre o abismo.

Pois o sofrimento, pelo simples fato de existir, atesta uma inconformidade, se não um não conformismo à ordem estabelecida, e já assinala portanto de maneira irrecusável que há uma outra dimensão, irredutível aos «fatos», que a vida não poderia se reduzir à evidência bruta da sobrevivência inana. $\mathrm{O}$ que 


\section{EDITORIAL}

equivale a dizer que a esperança, o sonho, a arte, já habitam no âmago mesmo da desesperança, da dor e do «sufoco». E a partir dessa outra dimensão, o fato do sofrimento, por si só, já terá sempre julgado e condenado o estado atual das coisas.

Ponto importante a reter: essa força de resistência é uma força artista, plena de engenhosidade (sempre capaz de criar algo a partir do nada), apta em particular a revirar uma situação adversa dada: a transmutar a miséria em força, o desamparo em recurso, a astenia em paixão e em vitalidade, o luto em energia de luta. (Num outro registro: «Elevar a impotência ao impossível»: tal é precisamente o desafio da cura, dizia Lacan [2001].) É nesse sentido que o seu acrobatismo contém um formidável potencial de utopia.

A corda bamba acima do abismo está estendida, portanto, entre o que é, a dita «realidade», e uma existência outra, desejada, para além do que é, cuja realização é prometida e que, contra tudo, se trata de efetuar. É a essência do que se chama esperança. Que o advento de um mundo outro é possível, tal é precisamente a aposta do funâmbulo, o artista da ultrapassagem dos limites, empenhado em tornar possível o impossível.

\section{4}

Poder de reviravolta, força de resistência artista, acrobática, paixão do possível: compreende-se que a figura tutelar do hino da anistia política seja Charlie Chaplin. O homem do povo, filho da Boêmia, poeta saltimbanco, mestre em expedientes num mundo hostil onde a figura moderna da política cai em ruína. Chaplin, o suspeito (título do belo texto de Hannah Arendt [1987] sobre o pária), resta aí o portador de um potencial de utopia inesgotável, apesar de tudo. Sempre guiado por um sentido aguçado da injustiça que a sociedade moderna inflige ao ser humano e às suas possibilidades. A tal ponto que isso levou finalmente Chaplin a ser forçado a deixar a América macarthista...

Vê-se claramente aí a fonte de onde este potencial tira a sua força: é a coisa que em cada um excede as palavras, que «siste», insiste e faz resistir à violência da instituição social da «realidade»; é o seu resto de infância que sofre e que ainda espera, indomesticável. O inumano em nós segundo Lyotard (1988).

Freud (1931) dizia que Chaplin interpreta sempre a mesma cena: a da infância desamparada, hilflosen, traumatizada pela injustiça, pela privação e pela humilhação. Mas convém acrescentar: e que ao mesmo tempo desenvolve tesouros de criatividade, de acrobacia para responder à sua condição, para transformar a sua desventura em arte de viver. (É essa lógica da transmutação 
que Samuel Beckett ${ }^{5}$ levará à sua plena realização, através da galeria dos párias filósofos, Watt, Molloy, Vladimir, Estragon e todos os outros.)

O ponto culminante desta arte acrobática é um exercício espiritual, musical, visando aprender a viver à beira do abismo. É notável no caso que o hino da anistia e dos exilados brasileiros seja inspirado do começo ao fim por uma melodia que se chama Smile, composta para o filme Modern times. Smile é um apelo; ela demanda ao ser amado que ele se exerça a sorrir, a fim de exorcizar as adversidades da existência. No que essa exortação já se inscreve numa operação de transformação. É uma micro-acrobacia sutil (musical) do corpo-psique com vistas a modificar o seu estado de alma.

A «técnica» preconizada por esse conselho ético, por essa therapeia, é comum à arte do mímico e à intuição pascaliana: efetue tal gesto, e você acabará por experimentar o estado afetivo que está associado a ele. Sorria e você não se deixará se abater, você se reerguerá e encontrará uma razão de viver.

Não é anódino que Smile seja ela mesma inspirada pelo ar dos amantes da Tosca de Puccini («Qual occhio al mondo...»). Mas ela modifica o tema do dueto: do motivo dos olhos ardentes da amante para o motivo do sorriso que faz falta no rosto amado, exposto às condições da vida industrial e da Grande Depressão dos anos 1930. O amante demanda e espera ainda todavia o sorriso, do qual ele faz um exercício sobre si, um ato de resistência com vistas a uma arte de viver no contexto geral dos desafios, das injustiças e dos desastres dos tempos modernos.

Fazendo isto, ele salva o sentido da paixão do possível e mantém aberto, contra ventos e marés, um horizonte de esperança onde cintilam ainda os sinais frágeis de uma existência outra, prometida.

Compreende-se, a partir daí, que o hino da anistia política tenha se inspirado de Smile, quarenta anos depois. No fundo da «noite do Brasil» sob a ditadura, que evoca a canção, feita de perseguições, torturas, desaparecimentos, laços desfeitos e angústia - eis que surge, como em sonho, a pequena silhueta do vagabundo, clown equilibrista de chapéu-coco, o encantador de Smile, sempre prestes a dançar na corda bamba - na mesma linha melódica. A sua energia de infância, verdadeiro princípio de esperança passando ao ato, irradia sobre todo o hino da anistia dos exilados. Sua paixão do possível, seu potencial de utopia impregnam toda a canção e provam no final que a arte, a resistência acrobática, continua.

${ }^{5}$ Ver por exemplo Watt (1942), a trilogie Molloy (1948), Malone meurt (1948) e L'innommable (1949), e naturalmente a peça En attendant Godot (1948). Todos esses textos foram publicados em francês pelas Éditions de Minuit a partir de 1951. 


\section{EDITORIAL}

\section{5}

Certamente não estamos mais nos tempos modernos, mas nos tempos chamados pós-modernos. Tempos, como já foi dito, da hegemonia do liberalismo cognitivista e do mercado mundial do conhecimento, das democracias midiáticas e da desorientação geral. Neste contexto, a paixão do possível é sufocada, literalmente excluída na agitação do business e dos imperativos técnicos do sistema. O smile, figura moderna desta paixão, cedeu o espaço e o tempo ao keep smiling automático, vazio, careta «lúdica» de uma felicidade administrada que invade as telas que nos cercam por todos os lados.

Mas como esses dados históricos, contingentes, os dados de nosso destino atual, seriam suscetíveis de mudar o que quer que seja no que tange à força de resistência nativa, indomável? Essa força constitui isto que, em cada um, não é mutável nem permutável.

O senso inato que o humano tem do que lhe falta, do que ele não é, mas do qual ele todavia tem uma ideia e o desejo - essa tensão interior, e a paixão de outra coisa que ela inspira —, o impelem a transgredir os limites, a ir para além de si mesmo. Este é o traço fundamental do humano. Como atesta a meditação que vai do teatro trágico à psicanálise e à «ética da psicanálise». Ele é o fato disto que em cada um excede e insiste, espera e às vezes desespera, insaciável e invencível. No que o humano é, com efeito, constitutivamente acrobata, equilibrista.

Após o declínio das Luzes e a ruína da visão política do mundo (incluindo a sua versão radical, dita revolucionária), resta este excesso intrínseco, irredutível à lei da troca e da permutabilidade geral, escapando à imanência do «mundo dos negócios».

A esperança é um dos nomes desta obstinação. Por definição, ela está em exceção, em excesso quanto à lei do sistema e à sua regulação. Ela não poderia ser vencida portanto pelo que está aí. Ela é o amor do que ainda não aconteceu.

\section{Referências}

Arendt, H. (1987). «Charlie Chaplin: Der Suspekte». In Die verborgene Tradition. Acht Essays (1932-1948). Trad. fr. S. Courtine-Denamy, "Charlie Chaplin: le suspect».In La Tradition cachée. Le juif comme paria (p. 200-202). Paris: Christian Bourgois.

Bloch, E. (1976). Das Prinzip Hoffnung (1938-1947, 1954-1959). Trad. fr. Françoise Wuilmart, Le Principe espérance (3 vol., tome 1). Paris: Gallimard. 
Freud, S. (1931). Carta a Max Schiller de 26 de março de1931. In: Sigmund Freud Museum. Recuperado de: $<$ https://www.freud-museum.at/de/sigmund-und-annafreud/sigmund-freud-online.html $>$.

Lacan, J. (2001). «...Ou pire»: compte-rendu du séminaire 1971-1972 pour l'Annuaire de l'EPHE. In Autres écrits (p. 547-559). Paris: Seuil.

Lyotard, J.-F. (1988). L'inhumain. Causeries sur le temps. Paris: Galilée.

Sloterdijk, P. (2011). Du musst dein Leben ändern. Ein Anthropotechnik (2009). Trad. fr. Olivier Mannoni. Tu dois changer ta vie (p. 93 e passim). Libella-Maren Sell.

Citação/Citation: Prado, P. (2018, junho). Editorial. A resistência equilibrista. Universidade, clínica e política. Revista Latinoamericana de Psicopatologia Fundamental, 21(2), 219-228. http://dx.doi.org/10.1590/1415-4714.2018v21n2p219.1

Editores do artigo/Editors: Profa. Dra. Ana Maria Rudge e Profa. Dra. Sonia Leite

Recebido/Received: 15.03.2018 / 03.15.2018 Aceito/Accepted: 20.04.2018 / 04.20.2018

Copyright: (C) 2009 Associação Universitária de Pesquisa em Psicopatologia Fundamental/ University Association for Research in Fundamental Psychopathology. Este é um artigo de livre acesso, que permite uso irrestrito, distribuição e reprodução em qualquer meio, desde que o autor e a fonte sejam citados / This is an open-access article, which permits unrestricted use, distribution, and reproduction in any medium, provided the original authors and sources are credited.

\section{Plínio W. Prado Jr.}

Ensina no Departamento de Filosofia da Universidade de Paris 8, ex-«Vincennes». Publicou, em torno do mesmo assunto, Le Príncipe d'Université, Editions Lignes, Paris, 2009 (versão original em linha: Le Principe d'Université).

Contato: Plínio PRADO | Universite Paris-8, France - Academia.edu

This is an open-access article, which permits unrestricted use, distribution, BY-NC and reproduction in any medium for non-commercial purposes provided the original authors and sources are credited. 